Case Report

\title{
An Intact Dopamine Sensitivity in the Brain: A Necessity to Recover Hyperprolactinemia and Galactorrhea in a Female Hemodialysis Patient?
}

\author{
Eva Philipse, ${ }^{1}$ Ester Philipse, ${ }^{2}$ Theodorus Twickler, ${ }^{1}$ Amaryllis Van Craenenbroeck, \\ Marie Madeleine Couttenye, ${ }^{2}$ and Luc Van Gaal ${ }^{1}$ \\ ${ }^{1}$ Department of Endocrinology, University Hospital of Antwerp, Edegem, Belgium \\ ${ }^{2}$ Department of Nephrology, University Hospital of Antwerp, Edegem, Belgium \\ Correspondence should be addressed to Eva Philipse; eva.philipse@uza.be
}

Received 27 February 2017; Accepted 13 June 2017; Published 16 July 2017

Academic Editor: Władysław Sułowicz

Copyright (C) 2017 Eva Philipse et al. This is an open access article distributed under the Creative Commons Attribution License, which permits unrestricted use, distribution, and reproduction in any medium, provided the original work is properly cited.

A female hemodialysis patient with galactorrhea due to hyperprolactinemia was treated with different dialysis modalities to assess the effect on prolactin levels. A single session of both high-flux hemodialysis and hemodiafiltration resulted in decreased prolactin levels $(16,6 \%$ and $77,2 \%$, resp.). However, baseline prolactin levels measured immediately before the next dialysis session did not change markedly. After cabergoline treatment was started, prolactin levels normalized and galactorrhea disappeared. Thus, dopaminergic inhibition of prolactin secretion might be reduced in patients with end-stage renal disease. This dopaminergic resistance could be an important mechanism of hyperprolactinemia in hemodialysis patients and its subsequent treatment strategies.

\section{Background}

Hyperprolactinemia is the most common cause of galactorrhea in women. In patients with end-stage renal disease (ESRD), the prevalence of hyperprolactinemia in men and women ranges from 30 to $65 \%$. Nevertheless, little is known about the mechanism of hyperprolactinemia in this patient population.

Prolactin has different isoforms with a molecular size ranging from 23 to $150 \mathrm{kDa}$. The monomeric $23 \mathrm{kDa}$ prolactin isoform is biologically the most active form. One could speculate that large prolactin isoforms accumulate in patients with a reduced renal clearance. However, hyperprolactinemia in patients undergoing renal replacement therapy (RRT) does not consist abundantly of macroprolactin $(>50 \mathrm{kDa})$ isoforms [1]. However, the long-term effect of RRT on prolactin levels has never been studied.

As proof of concept, we evaluated prolactin levels in a female hemodialysis patient with galactorrhea due to hyperprolactinemia who underwent different dialysis modalities to assess the effect of conventional high-flux hemodialysis (HD) and postdilution hemodiafiltration (HDF) on prolactin levels.

\section{Case Report}

A 52-year-old female hemodialysis patient with galactorrhea due to hyperprolactinemia was treated with cabergoline (dopamine $\mathrm{D}_{2}$ receptor agonist). The patient had no residual renal function. Because of recent cardiothoracic surgery, cabergoline was discontinued. One month after surgery, prolactin level was only slightly elevated $(48.1 \mu \mathrm{g} / \mathrm{l}$, reference level: $2.2-30.3 \mu \mathrm{g} / \mathrm{l}$ ) without any complains of galactorrhea. Cabergoline treatment was not restarted. A few months later, her dialysis modality was switched from HD to HDF because of persistent uremic complaints. Unfortunately, she did not notice any effect of this change after three months and dialysis modality was reversed to HD. Meanwhile sertraline was started because of a depression. 


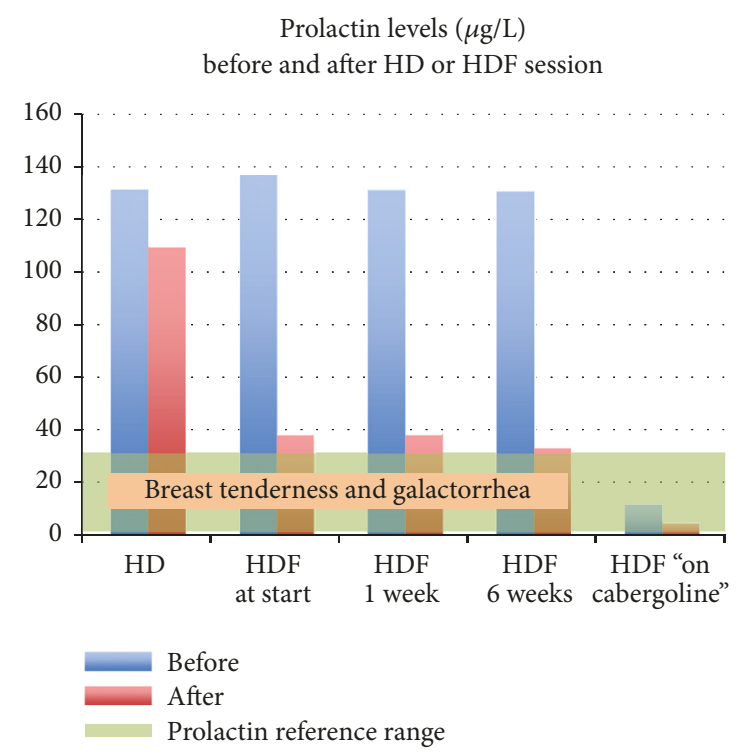

FIGURE 1: Prolactin levels ( $y$-axis) before and after four-hour HD and HDF session (with or without cabergoline). Prolactin reference range: $2.2-30.3 \mu \mathrm{g} / \mathrm{l}$.

One month after the cessation of HDF, she presented again with complaints of galactorrhea. The patients' thyroid function was normal (TSH: $0.73 \mathrm{mU} / 1$, reference level: $0.36-$ $3.74 \mathrm{mU} / \mathrm{l}$ ) and she is postmenopausal (FSH: $28.5 \mathrm{U} / \mathrm{l}$, postmenopausal reference level: 19.3-101 U/l; LH: $27.4 \mathrm{U} / 1$, postmenopausal reference level: 8.6-61.8 U/l; estradiol: $128 \mathrm{ng} / \mathrm{l}$; postmenopausal reference level: < $138 \mathrm{ng} / \mathrm{l})$. Prolactin levels immediately before and after a HD session were $131.1 \mu \mathrm{g} / \mathrm{l}$ and $109.3 \mu \mathrm{g} / \mathrm{l}$, respectively. At the moment of analysis, dialysis vintage was 94 months and dialysis adequacy targets were reached (eKT/V 1.64 and URR 78\%). Breast ultrasonography showed no abnormalities and there was no pituitary mass on nuclear magnetic resonance imaging. Diagnosis of hyperprolactinemia due to ESRD in combination with sertraline therapy was made.

Since galactorrhea reappeared shortly after HDF was switched to $\mathrm{HD}$, we hypothesized that HDF removes prolactin more effectively than HD. Prolactin levels immediately before and after a HDF session were $136.9 \mu \mathrm{g} / \mathrm{l}$ and $38.0 \mu \mathrm{g} / \mathrm{l}$, respectively. However, after six-week treatment with HDF, galactorrhea persisted and prolactin levels immediately before and after a HDF session were $130.7 \mu \mathrm{g} / \mathrm{l}$ and $33.2 \mu \mathrm{g} / \mathrm{l}$, respectively. Dialysis adequacy targets on HDF were also reached (eKT/V 1.81 and URR 83\%). Treatment with cabergoline was restarted, after which galactorrhea resolved and prolactin levels normalized to $11.5 \mu \mathrm{g} / \mathrm{l}$ and $4.4 \mu \mathrm{g} / \mathrm{l}$ before and after a HDF session, respectively (Figure 1). In all the measured prolactin levels, there was no macroprolactin present.

\section{Discussion}

The increase in prolactin levels in patients on RRT could be partly explained by reduced renal clearance of prolactin $[2,3]$. HD is known to remove small molecules $(0-0.5 \mathrm{kDa})$ through diffusion. HDF combines diffusion and convection and improves the clearance of middle-sized molecules (0,5-15 kDa) such as $\beta 2$-microglobulin (11.8 kDa) [4].

Hitherto, no comparison was made between $\mathrm{HD}$ and HDF regarding prolactin clearance. In our patient, we found significantly lower prolactin levels immediately after a HDF session compared to a HD session, while dialysis adequacy between both is quasi-similar. However, baseline prolactin levels, measured immediately before a HD or HDF session, did not change markedly and galactorrhea persisted. Stimulation of the $D_{2}$ receptor was needed to obtain physiological prolactin levels and total clinical recovery. Delayed disappearance of galactorrhea after normalization of prolactin could be expected. Al-Husaynei et al. described that galactorrhea disappeared in $100 \%$ of all women with hyperprolactinemic amenorrhea after eight-week cabergoline treatment [5].

An additional factor contributing to sustained hyperprolactinemia in patients with ESRD could be due to an enhanced prolactin secretion by the pituitary. The secretion of prolactin is predominantly regulated by dopaminergic inhibition and this mechanism could be blunted in patients on RRT, also called lactotrophic resistance [2-4]. The mechanism behind that has not been fully elucidated yet (Figure 2). Sievertsen et al. [6] suggested some mechanisms. First, there could be a uremic factor which could not be removed by RRT and interferes with the binding of local dopamine to its receptor. Second, the quality and/or quantity of the dopamine receptors could be changed. Finally, modification in postreceptor metabolism of the dopamine receptor could be considered [6]. In addition, an increase in prolactin level is a known secondary effect of sertraline treatment. However, whether selective serotonin-reuptake inhibitors (SSRIs) and thus sertraline could cause a clinically overt hyperprolactinemia is still controversial [7, 8]. Against that background, 


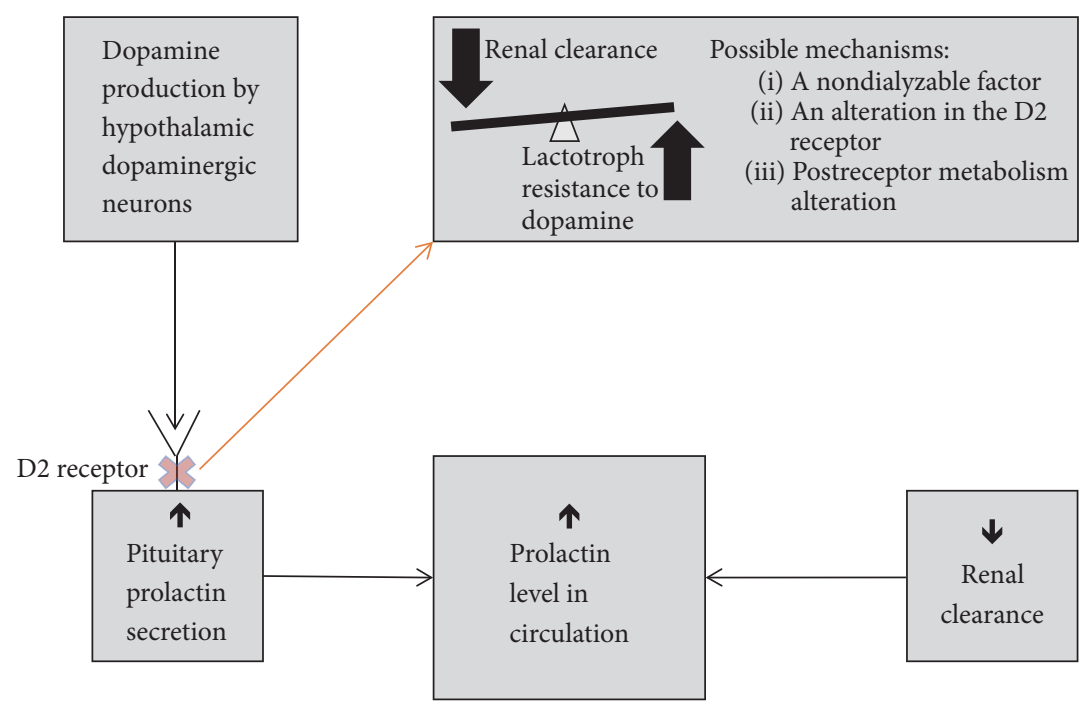

FIGURE 2: Concept to explain hyperprolactinemia in end-stage renal failure.

Kim and Park describe prevalence of SSRI-induced hyperprolactinemia of $10.9 \%$ [7]. A possible mechanism is that a SSRI could act as a dopamine-reuptake inhibitor $[7,8]$.

\section{Conclusion}

In addition to the reduced renal clearance of prolactin, lactotrophic resistance is a major cause of hyperprolactinemia in patients on RRT. Stimulation of the $\mathrm{D}_{2}$ receptor, rather than increased renal clearance alone, is needed for biochemical and clinical response. It merits further investigation to elucidate the underlying mechanism.

\section{Conflicts of Interest}

The authors declare that they have no conflicts of interest.

\section{References}

[1] D. Yavuz, G. Topçu, Ç. Özener, S. Akalin, and Ö. Sirikçi, "Macroprolactin does not contribute to elevated levels of prolactin in patients on renal replacement therapy," Clinical Endocrinology, vol. 63, no. 5, pp. 520-524, 2005.

[2] G. Ramirez, W. M. O'Neill, H. A. Bloomer, and W. Jubiz, "Abnormalities in the regulation of prolactin in patients with chronic renal failure," The Journal of Clinical Endocrinology \& Metabolism, vol. 45, no. 4, pp. 658-661, 1977.

[3] H. Bry-Gauillard, P. Touraine, M.-F. Mamzer-Bruneel, A. Simoes-Vaz, F. Kuttenn, and C. Legendre, "Complete regression of a major hyperprolactinaemia after renal transplantation," Nephrology Dialysis Transplantation, vol. 14, no. 2, pp. 466-468, 1999.

[4] P. B. Kerr, A. Argiles, J.-L. Flavier, B. Canaud, and C. M. Mion, "Comparison of hemodialysis and hemodiafiltration: a longterm longitudinal study," Kidney International, vol. 41, no. 4, pp. 1035-1040, 1992.

[5] A. J. Al-Husaynei, I. H. Mahmood, and Z. S. Al-Jubori, "Comparison of the effects of cabergoline and bromocriptine in women with hyperprolactinemic amenorrhea," Middle East Fertility Society Journal, vol. 13, no. 1, pp. 33-38, 2008.

[6] G. D. Sievertsen, V. S. Lim, C. Nakawatase, and L. A. Frohman, "Metabolic clearance and secretion rates of human prolactin in normal subjects and in patients with chronic renal failure," Journal of Clinical Endocrinology and Metabolism, vol. 50, no. 5, pp. 846-852, 1980.

[7] S. Kim and Y.-M. Park, "Serum prolactin and macroprolactin levels among outpatients with major depressive disorder following the administration of selective serotonin-reuptake inhibitors: A cross-sectional pilot study," PLoS ONE, vol. 8, no. 12, Article ID e82749, 2013.

[8] D. La Torre and A. Falomi, "Pharmacological causes of hyperprolactinemia," Therapeutics and Clinical Risk Management, vol. 3, no. 5, pp. 929-951, 2007. 


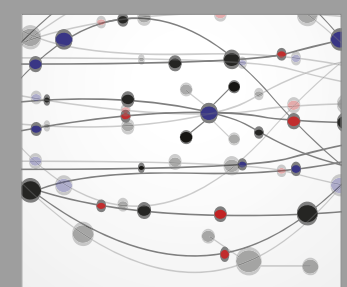

The Scientific World Journal
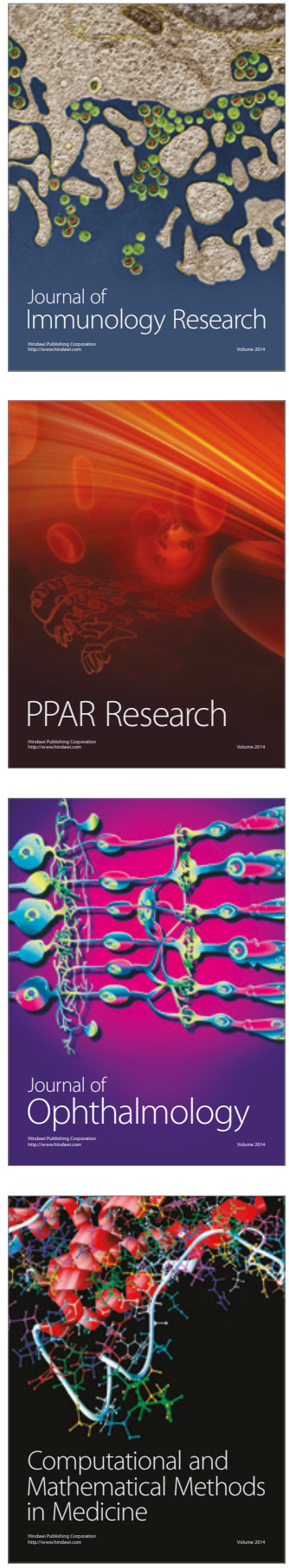

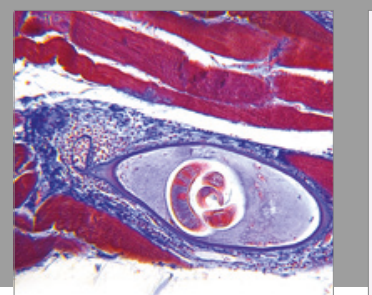

Gastroenterology Research and Practice
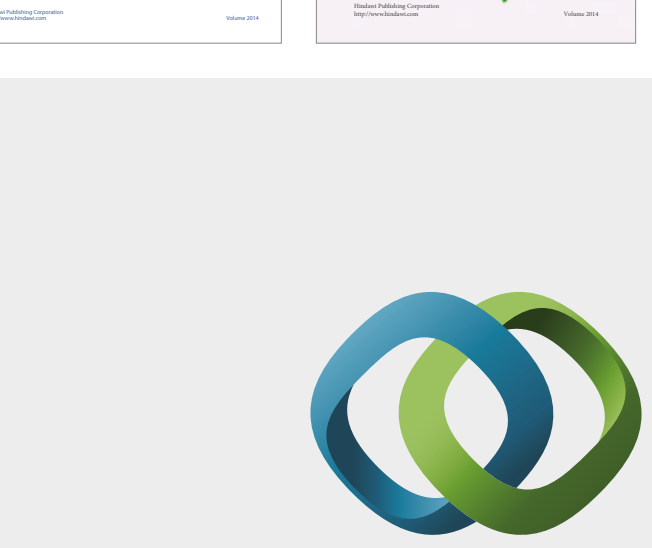

\section{Hindawi}

Submit your manuscripts at

https://www.hindawi.com
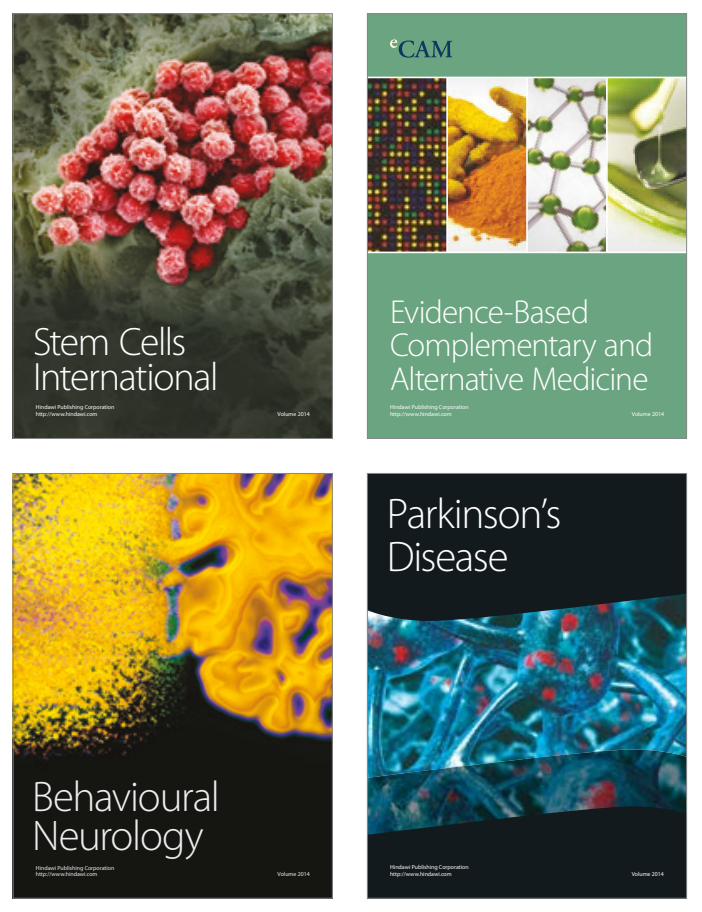
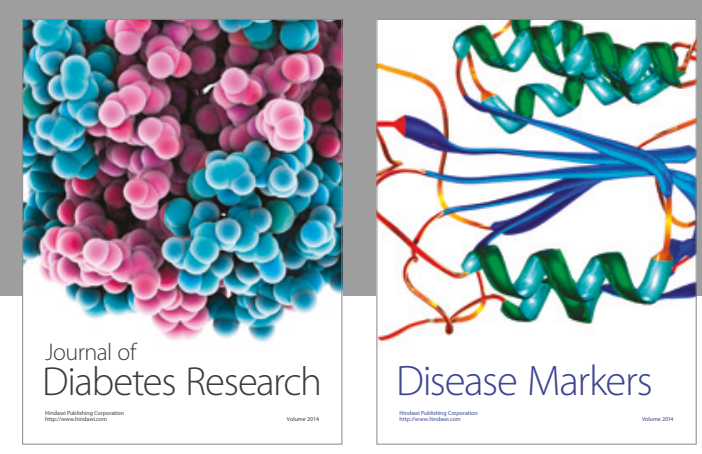

Disease Markers
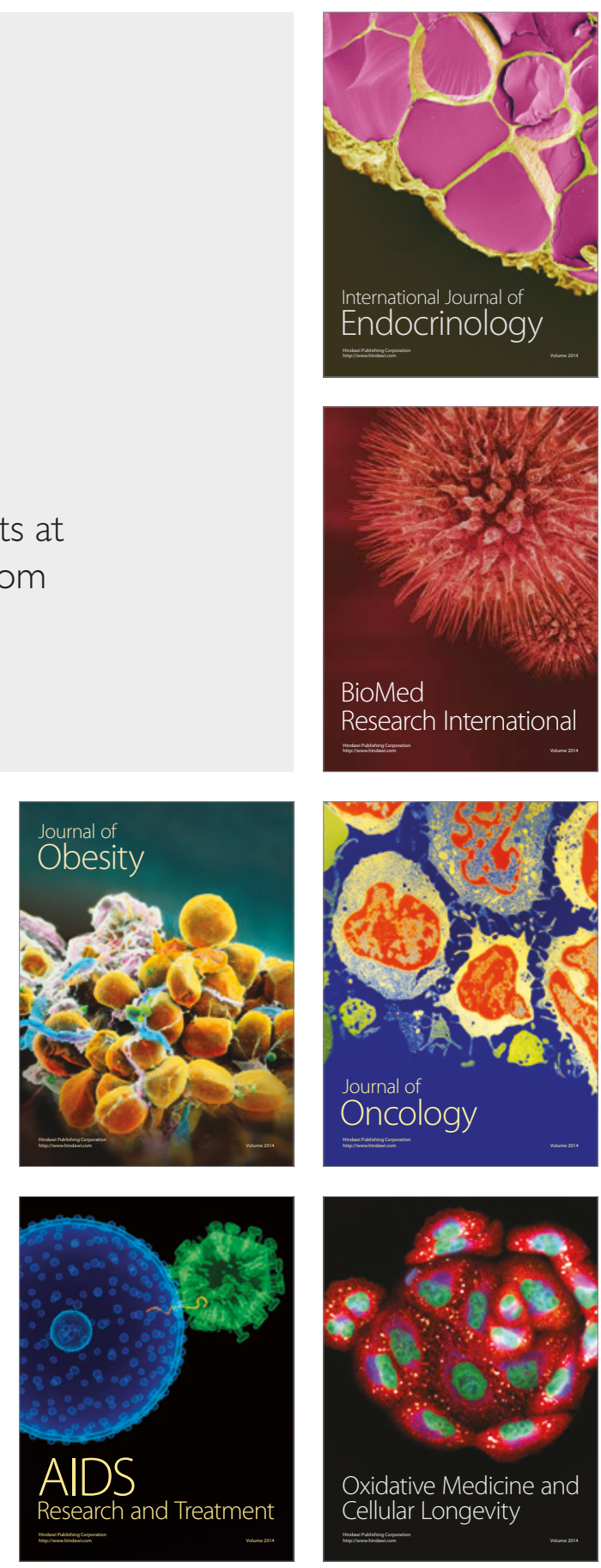